\title{
"Body \& Brain": effects of a multicomponent exercise intervention on physical and cognitive function of adults with dementia - study protocol for a quasi- experimental controlled trial
}

\author{
Joana Carvalho ${ }^{1,2}$, Flávia Borges-Machado 2*0, Duarte Barros², Arnaldina Sampaio², Inês Marques-Aleixo 2,3, \\ Lucimere Bohn ${ }^{2,3}$, Andreia Pizarro ${ }^{2}$, Laetitia Teixeira ${ }^{4}$, José Magalhães ${ }^{1,2}$ and Óscar Ribeiro ${ }^{5}$
}

\begin{abstract}
Background: Dementia is a leading cause of death and disability that was declared as one of the greatest health and social care challenges of the twenty-first century. Regular physical activity and exercise have been proposed as a non-pharmacological strategy in disease prevention and management. Multicomponent Training (MT) combines aerobic, strength, balance and postural exercises and might be an effective training to improve both functional capacity and cognitive function in individuals with dementia (IwD). Nevertheless, data on the effects of MT in IwD are still limited and the extent to which IwD can retain improvements after an exercise intervention still needs to be elucidated. The aim of "Body \& Brain" study is to investigate the effects of a 6-month MT intervention and 3month detraining on the physical and cognitive function of IwD. Additionally, we aim to explore the impact of this intervention on psychosocial factors and physiologic markers related to dementia.

Methods: This study is a quasi-experimental controlled trial using a parallel-group design. The study sample consists of community-dwelling individuals aged $\geq 60$ years who are clinically diagnosed with dementia or major neurocognitive disorder. Participants will be either allocated into the intervention group or the control group. The intervention group will participate in MT biweekly exercise sessions, whereas the control group will receive monthly sessions regarding physical activity and health-related topics for 6 months. The main outcomes will be physical function as measured by the Short Physical Performance Battery (SPPB) and cognitive function evaluated using the Alzheimer Disease Assessment Scale Cognitive (ADAS-Cog) at baseline, after 6-months and 3-months after the end of intervention. Secondary outcomes will be body composition, physical fitness, daily functionality, quality of life, neuropsychiatric symptoms and caregiver's burden. Cardiovascular, inflammatory and neurotrophic blood-based biomarkers, and arterial stiffness will also be evaluated in subsamples.

(Continued on next page)
\end{abstract}

\footnotetext{
* Correspondence: f993 machado@live.com.pt

${ }^{2}$ CIAFEL, Centro de Investigação em Atividade Física, Saúde e Lazer, Universidade do Porto, Rua Dr. Plácido Costa 91, 4200-450 Porto, Portugal

Full list of author information is available at the end of the article
}

(C) The Author(s). 2021 Open Access This article is licensed under a Creative Commons Attribution 4.0 International License, which permits use, sharing, adaptation, distribution and reproduction in any medium or format, as long as you give appropriate credit to the original author(s) and the source, provide a link to the Creative Commons licence, and indicate if changes were made. The images or other third party material in this article are included in the article's Creative Commons. licence, unless indicated otherwise in a credit line to the material. If material is not included in the article's Creative Commons licence and your intended use is not permitted by statutory regulation or exceeds the permitted use, you will need to obtain permission directly from the copyright holder. To view a copy of this licence, visit http://creativecommons.org/licenses/by/4.0/ The Creative Commons Public Domain Dedication waiver (http://creativecommons.org/publicdomain/zero/1.0/) applies to the data made available in this article, unless otherwise stated in a credit line to the data. 
(Continued from previous page)

Discussion: If our hypothesis is correct, this project will provide evidence regarding the efficacy of MT training in improving physical and cognitive function and give insights about its impact on novel molecular biomarkers related to dementia. This project may also contribute to provide guidelines on exercise prescription for IwD.

Trial registration: ClinicalTrials.gov - identifier number NCT04095962; retrospectively registered on 19 September 2019.

Keywords: Neurocognitive disorder, Multimodal, Functionality, Cognition

\section{Background}

Dementia is considered one of the main age-related health problems impacting the modern society $[1,2]$. Also designated as major neurocognitive disorder, these umbrella terms are used to describe a set of diseases that are mostly chronic or progressive, affecting the brain and several cognitive functions [3, 4]. By 2050, it is expected that 132 million people will suffer from dementia worldwide [1]. Therefore, the World Health Organization (WHO) has already recognized this condition as a global health priority [5] and alerted countries for the need to develop and implement national intervention plans to prevent, treat and care for dementia [6]. In Portugal, the prevalence rate for dementia in 2017 was $9.23 \%$ in community-dwelling older adults [7].

Age is the primary non-modifiable risk factor for dementia [8]. Livingston et al. (2020) described 12 potentially modifiable risk factors that, when addressed might prevent or delay up to $40 \%$ of dementia cases [2]. Of those, addressing physical inactivity (e.g., by increasing the levels of physical activity), particularly in later life, may be a potential strategy to prevent, or even delay the progression of cognitive impairment due to its effect on underlying physiologic mechanisms: the indirect effects on general cardiovascular health/fitness and neurological direct effects [9-11].

Individuals diagnosed with dementia (IwD) not only exhibit a significant decline in one or more cognitive domains that interfere with the person's ability to perform activities of daily living (ADL), but also tend to reveal increased declines on physical fitness, as impaired aerobic capacity, muscle strength, agility, gait and balance [1214]. Skinner, Ellis \& $\mathrm{Pa}$ (2018) stated that exercise may positively impact IwD's cognition, quality of life, functional status, sleep, mood and physical function [11], being these positive outcomes related to several cellular and molecular alterations [15]. Additionally, evidences suggest that exercise can counteract dementia-related pathogenic changes by preserving neuroplasticity trough neurogenesis, synaptogenesis and angiogenesis [15]. Hence, increasing data advocate regular moderate-intensity exercise as an effective strategy to improve general health status, reducing vascular risk factors, obesity, levels of inflammatory markers, improving metabolism and brain health in older adults with dementia [16]. However, results regarding exercise effects on cognitive function are still heterogeneous [17-19].

Although exercise interventions for IwD seem to be feasible and well tolerated, resulting in positive effects on ADL functionality for people at mild-to-moderate stages $[17,18]$, the therapeutic role of physical activity, particularly exercise, after dementia diagnosis still needs further evidence [20-22], - especially when considering community-based contexts and caregivers as participants on exercise sessions [23]. It also matters to highlight that the dose-dependent relationship remains unclear $[11,18,24]$. Therefore, research is needed to identify the triad: stage/type of dementia, FITT variables (frequency, intensity, type and time) of exercise intervention, and target outcome [11, 25].

Regarding exercise modality, Multicomponent Training (MT) [26] - combining aerobics, strength and balance exercises - seems to be effective at improving functional and cognitive performances in older adults with neurodegenerative disorders, particularly dementia [27-29]. Exercise programs previously developed by our group confirmed that a 6-month MT intervention can positively impact the physical and cognitive function of institutionalized older adults with Alzheimer's Disease (AD) $[30,31]$ and can be beneficial in physical fitness and ADL functionality performance among community-dwelling patients $[25,32]$. However, the extent to which IwD can retain these improvements after the cessation of $\mathrm{MT}$ intervention still need to be elucidated [33] in order to understand how detraining affects functionality and cognition following the cessation of MT stimulus.

In addition to the most common analysis on cognition, physical fitness, daily functionality, neuropsychiatric symptoms, quality of life and caregivers' burden [18, 3436], several other parameters need to be further explored when considering the benefits of MT. These include the effect of exercise on body composition, cardiorespiratory fitness, vascular, inflammatory and neurotrophic bloodbased biomarkers, and arterial stiffness.

The primary purpose of this study is to investigate the effects of a 6-month MT exercise intervention and 3months of detraining on physical and cognitive function of older adults diagnosed with dementia. Secondarily, we aim to explore potential positive effect of MT exercise on IwD psychosocial and physiological outcomes. We hypothesize that exercise positively modulates body 
composition (e.g., by increasing lean mass and decreasing adiposity) and therefore may improve physical fitness and function. Additionally, it is described that exercise enhances cerebrovascular plasticity, peripheral biomarkers associated with brain blood flow and (neuro)inflammation, consequently attenuating cognitive decline or even improving cognitive function. The concomitant enhancements of physical and cognitive function in individuals with dementia may help to preserve or improve their functionality in ADL and manage behavioral and psychological symptoms of dementia (BPSD), reducing the caregiver's burden and leading to improvements in quality of life.

\section{Methods and analysis}

The "Body \& Brain" study is registered with the US National Institutes of Health clinical trials registry (ClinicalTrials.gov identifier number NCT04095962). This protocol report complies with the Standard Protocol Items: Recommendations for Interventional Trials (SPIRIT) 2013 checklist: recommended items to address in a clinical trial protocol and related documents [37].

\section{Trial design}

This study is a multicenter quasi-experimental controlled trial with a parallel design, that will be conducted in a wide-ranging public and private settings (e.g., daycare centers and local community centers) in the Porto metropolitan area, Portugal. Participants will be recruited from community programs, daycare centers, psychiatric hospitals and clinics (i.e., outpatients followed within psychiatry or neurology specialists), Alzheimer's and caregivers' associations, municipalities, local journals, and social media. Advertisements will be made via phone calls, emails, informative flyers and presential and online meetings. In order to motivate and clarify concerns about the exercise sessions, a short MT session will be provided to exemplify and illustrate a typical session for individuals with dementia.

Eligible participants and caregivers will receive a complete explanation of the study purposes, risks and procedures. Following the best ethical procedures, informed consent will be obtained from interested dementia participants and from their main caregivers/legal representatives/significant person. After agreeing to participate and according to personal availability, participants will be allocated into a 6-month MT intervention (IG) or into a social activity group (CG) (see Fig. 1). All CG participants will be offered the possibility to participate in an exercise program after the end of the study cycle.

Participants will be assessed at baseline, after 6-month of intervention, and 3-month follow-up after the end of intervention (Table 1). At baseline, sociodemographic (e.g., age and years of formal education), general clinical data (e.g., presence of comorbidities, pharmacological treatment, and falls) will be collected through a structured questionnaire, and dementia rating severity evaluation will be performed trough the Clinical Dementia Rating (CDR) outcome measurement [38]. During baseline assessments, participants will not be informed regarding to which group they belong. Data collection will be performed by well-trained and experienced researchers.

The same evaluator will be responsible to perform the same procedures along the three assessment periods, which will be subdivided in five separate moments (Table 2). The exercise professional who is going to provide the MT sessions will not be involved in any data collection.

\section{Participants}

\section{Eligibility criteria}

This study will include individuals aged $\geq 60$ years capable of walking autonomously without an assistive device or human assistance, and diagnosed with dementia or major neurocognitive disorder using accepted diagnostic criteria such as that established by the Diagnostic and Statistical Manual of Mental Disorders (DSM-IV-TR or DSM-5) [3], ICD-10 [39], or the NINCDS-ADRDA [40]. Potential participants must have been diagnosed by a physician for at least for 6-months. Participants diagnosed with Parkinson's disease, Frontotemporal disease, Lewy bodies' disease, Huntington's disease or other rare forms of dementia can be included in the study as long as they do not exhibit significant motor/functional limitations. The exclusion criteria comprise disorders or conditions in which exercise is contraindicated such as unstable or ongoing cardiovascular and/or respiratory disorder; hospitalized individuals and/or recovering from surgery or rehabilitation; and presenting an advanced stage of dementia (e.g., scored 3-points in CDR or $\leq 10$ points on MMSE) that could affect physical performance in the exercise training sessions or testing procedures.

\section{Sample size}

Sample size was estimated based on ANCOVA for the analysis of the differences [41]. To detect an adjusted 1 point $(\mathrm{SD}=2.1$ ) difference in SPPB after intervention between IG and CG with $80 \%$ power and an alpha level of 0.05 , a total of 110 participants (55 participants per group) will be needed, already accounting for an estimated dropout of $25 \%$. Sample size calculation was performed using G*Power 3.1.3 (Universität Düsseldorf, Düsseldorf, Germany) [42].

\section{Study intervention}

\section{Experimental group: exercise training}

The MT program will be conducted for 6 months, twice a week in $60 \mathrm{~min}$ sessions. Sessions will be divided in 


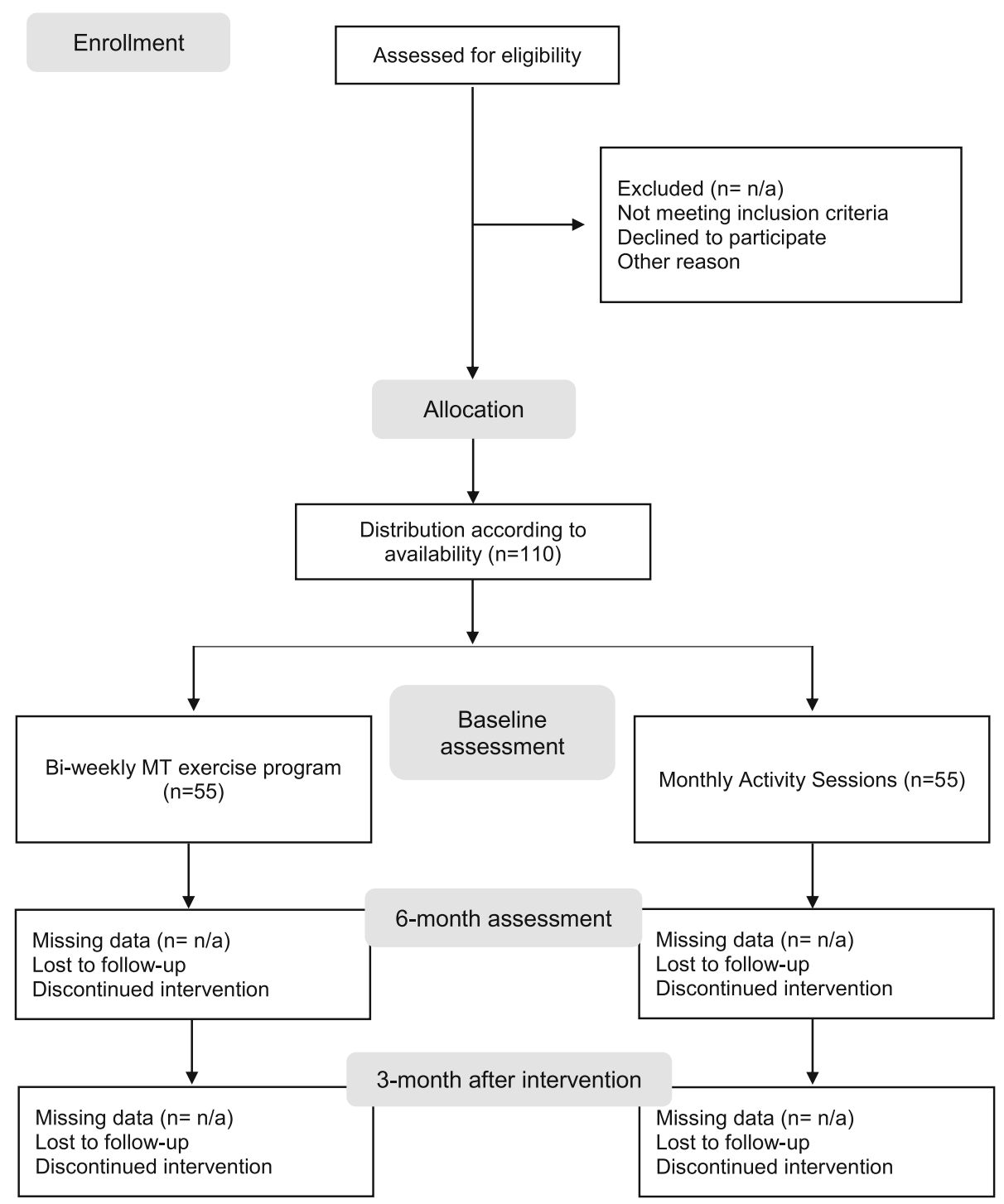

Fig. 1 Study Flow Diagram

warm-up (10 min, including slow walk, postural and mobility exercises for general activation, and stretching exercises), specific training (35-45 min, including balance/ coordination training, strength and aerobic exercises) and cool down (5 min with breathing and stretching exercises for the main worked joints and muscles) following the main guidelines recommended by the American College of Sports Medicine [43] and the WHO [44] (Table 3).

Well-designed, routine, simple, enjoyable and functional exercises will be preferred. A 1 month adaptation period, before the training program, will be implemented with the main purpose of promoting familiarization with exercises and socialization between participants [45]. New exercises should be introduced based only as a progression of previous well-known exercises. In the adaptation period the focus will be in learning the movements keeping a low intensity, of 40 to $50 \%$ of HRmax in the aerobic exercises and 1 set of 12 to 15 slow repetitions for the strength exercises.

Exercise prescription, implementation and evaluation will be performed by specialized exercise professionals. Furthermore, prior to the program implementation, those professionals will receive specific training concerning dementia (clinical features, signs and symptoms), challenging behaviors, communication strategies, and other related topics (e.g., safety issues) [46].

Sessions, involving 5 to 12 participants will be held in appropriate spaces and in a safe and calm environment to limit distractions and maximize the individuals' participation [46]. Sessions are going to be scheduled in the late morning or in early afternoon period, and the sports 
Table 1 Description of methods and/or instruments to evaluate IwD and/or their caregivers/significant person/proxy decision-maker

\begin{tabular}{|c|c|c|c|c|}
\hline & \multirow[t]{2}{*}{ Domain } & \multirow[t]{2}{*}{ Measure } & \multicolumn{2}{|c|}{ Data from } \\
\hline & & & $I w D$ & Caregiver \\
\hline \multirow[t]{3}{*}{ Screening } & \multicolumn{2}{|l|}{ Informed Consent } & $x$ & $x$ \\
\hline & \multicolumn{2}{|l|}{ Anamnesis (sociodemographic and general clinical data) } & & $x$ \\
\hline & \multicolumn{2}{|l|}{ Clinical Dementia Rating } & $x$ & $x$ \\
\hline \multirow[t]{4}{*}{ Primary $^{\mathrm{a}}$} & \multicolumn{2}{|l|}{ Cognition } & & \\
\hline & Cognitive Function & ADAS-Cog & $x$ & \\
\hline & \multicolumn{2}{|l|}{ Physical Fitness } & & \\
\hline & Lower Limb Function & SPBB & $x$ & \\
\hline \multirow[t]{35}{*}{ Secondary ${ }^{a}$} & \multicolumn{4}{|l|}{ Cognition } \\
\hline & \multirow[t]{2}{*}{ Cognitive Function } & MMSE & $x$ & \\
\hline & & TMT & & \\
\hline & \multicolumn{4}{|l|}{ Physical Fitness } \\
\hline & Cardiorespiratory Capacity & Modified Bruce Treadmill Test & $x$ & \\
\hline & Physical Fitness & SFT & $x$ & \\
\hline & Static Balance & One Leg Balance Test & $x$ & \\
\hline & Handgrip Strength & Handgrip Dynamometer & $x$ & \\
\hline & \multicolumn{4}{|l|}{ Body Composition and Anthropometry } \\
\hline & Body Mass & DXA (Hologic QDR 4500, Explorer model, version 12.4) & $x$ & \\
\hline & \multicolumn{4}{|l|}{ Total Fat-free Mass } \\
\hline & \multicolumn{4}{|l|}{ Fat Mass } \\
\hline & \multicolumn{4}{|l|}{ Appendicular Skeletal Mass Index } \\
\hline & Weight & Weighting Scale & $x$ & \\
\hline & Height & Stadiometer & $x$ & \\
\hline & Waist and Hip Circumferences & Measuring Tape & $x$ & \\
\hline & \multicolumn{4}{|l|}{ Quality of Life and ADL's Functionality } \\
\hline & \multirow[t]{2}{*}{ Basic and instrumental ADL } & Lawton \& Brody IADL Scale & & $x$ \\
\hline & & Barthel Index & & \\
\hline & Quality of Life & QoL-AD & $x$ & $x$ \\
\hline & \multicolumn{4}{|l|}{ Behavioral and Psychological Symptoms of Dementia } \\
\hline & Neuropsychiatric Symptoms and Caregiver Distress & NPI & & $x$ \\
\hline & \multicolumn{4}{|l|}{ Caregiver Burden } \\
\hline & \multirow[t]{2}{*}{ Caregiver Well-being and Subjective Burden } & CarerQol-7D & & $x$ \\
\hline & & CarerQol-Vas & & \\
\hline & \multicolumn{4}{|l|}{ Blood-based Biomarkers and Hemodynamics } \\
\hline & Systolic and Diastolic Blood Pressure & Digital Sphygmomanometer & $x$ & \\
\hline & Arterial Stiffness & Pulse Wave Velocity (SphygmoCor, AtCor Medical, Australia) & $x$ & \\
\hline & TG & Concentration in blood plasma & $x$ & \\
\hline & \multicolumn{4}{|l|}{$\mathrm{TC}$} \\
\hline & LDL-C & & & \\
\hline & $\mathrm{HDL}-\mathrm{C}$ & & & \\
\hline & $\mathrm{HbA} 1 \mathrm{c}$ & HPLC & & \\
\hline & BDNF & ELISA & $x$ & \\
\hline & VEGF & & & \\
\hline
\end{tabular}


Table 1 Description of methods and/or instruments to evaluate IwD and/or their caregivers/significant person/proxy decision-maker (Continued)

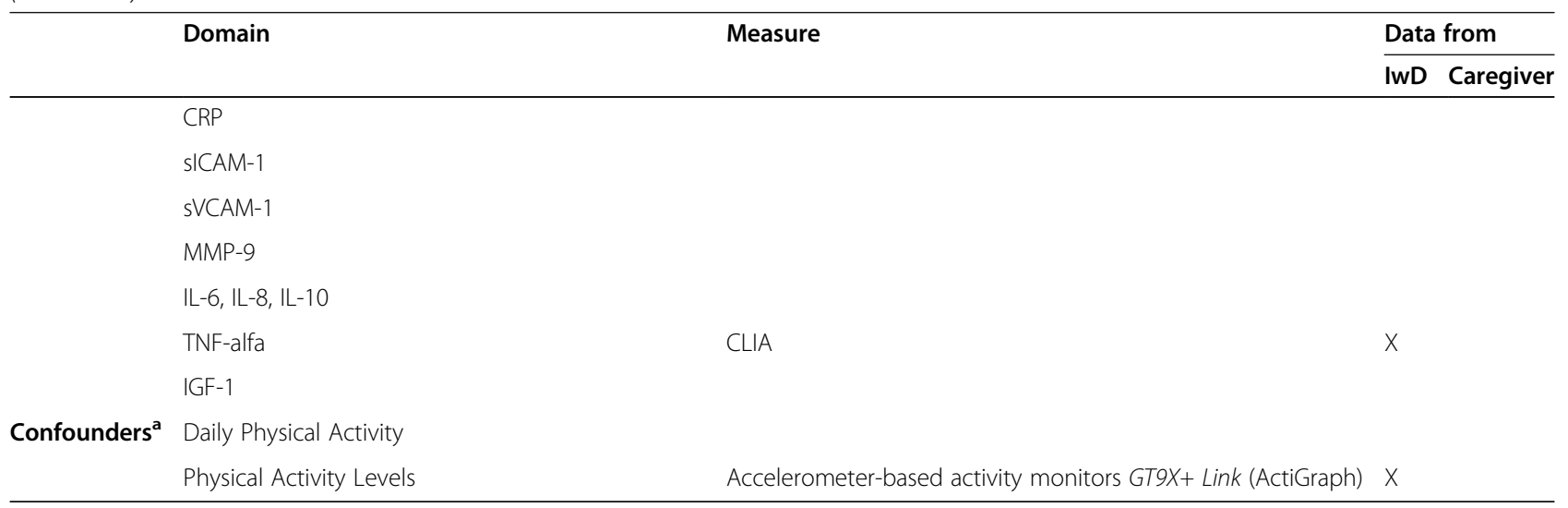

${ }^{\mathrm{a}} \mathrm{TO}$ Baseline, T1 After 6-month intervention, T2 3-month follow-up

equipment encompasses chairs, ground markers, strings, elastic resistance bands, dumbbells, hurdles, balance pads, balls, and steps. Whenever possible, sessions will be accompanied by music, particularly during the aerobic part, in order to confer appropriate exercises intensity and enthusiasm [45].

Balance exercises will gradually reduce the base of support and/or reduced sensory input as well as include dynamic movements that perturb the center of gravity. These progressions will occur when participants reach the time limit without losing control of the body. Also, focus on some easy coordination exercises and conscious control of the body will be performed.
Four to 6 multi-joint strength exercises involving major muscle groups will be included in each session. The number of repetitions will decrease from 10 to 12 to 8-10 with increasing load that could be lifted correctly to volitional fatigue. A rest period of $1^{\prime} 30^{\prime}-2$ " will be completed between each set.

Aerobic endurance will be attained with low impact exercises at $60-65 \%$ of HRMax implemented in two 5min periods. Intensity will increase progressively with increasing duration and HR until reaching 2 periods of 10 continuous minutes of exercise at 75 to $80 \%$ of HRmax. Sessions will be monitored using heart rate monitors [47], and whenever possible, the Modified Borg Scale of Perceived Exertion will be applied.

Table 2 Schedule for the different primary and secondary and outcomes, screening, and confounder evaluations of each assessment moment per evaluator

\begin{tabular}{|c|c|c|c|c|c|c|}
\hline $\begin{array}{l}\text { Assessment } \\
\text { moments per } \\
\text { evaluator }\end{array}$ & $\begin{array}{l}\text { Prior to Assessment (only } \\
\text { at baseline) }\end{array}$ & $\begin{array}{l}\text { 1st } \\
\text { Cognition \& } \\
\text { Functionality }^{\mathrm{a}}\end{array}$ & $\begin{array}{l}\text { 2nd } \\
\text { Cognition, } \\
\text { QoL \& } \\
\text { Physical } \\
\text { Fitness }^{\mathrm{a}}\end{array}$ & $\begin{array}{l}\text { 3rd } \\
\text { Physical } \\
\text { Activity } \\
\text { Level }^{\mathrm{a}}\end{array}$ & $\begin{array}{l}\text { 4th } \\
\text { ADL, QoL, } \\
\text { BPSD \& } \\
\text { Caregiver } \\
\text { Burden }^{\text {a }}\end{array}$ & $\begin{array}{l}\text { 5th } \\
\text { Body Composition, } \\
\text { Cardiorespiratory Fitness, } \\
\text { Hemodynamics \& Blood-based } \\
\text { Biomarkers }^{\mathrm{a}}\end{array}$ \\
\hline Evaluator 1 & CDR & $\begin{array}{l}\text { MMSE } \\
\text { TMT }\end{array}$ & $\begin{array}{l}\text { ADAS-Cog } \\
\text { QoL-AD } \\
\text { patient }\end{array}$ & & $\begin{array}{l}\text { QoL-AD } \\
\text { caregiver } \\
\text { Carer-QoL } \\
\text { NPI } \\
\text { Barthel Index } \\
\text { Lawton \& } \\
\text { Brody IADL } \\
\text { Scale }\end{array}$ & \\
\hline Evaluator 2 & & $\begin{array}{l}\text { SPPB } \\
\text { Handgrip } \\
\text { strength }\end{array}$ & $\begin{array}{l}\text { SFT One Leg } \\
\text { Balance Test }\end{array}$ & $\begin{array}{l}\text { 7-day } \\
\text { accelerometer- } \\
\text { based monitor }\end{array}$ & & \\
\hline Evaluator 3 & $\begin{array}{l}\text { Informed Consent and } \\
\text { anamnesis } \\
\text { (sociodemographic and } \\
\text { general clinical data) }\end{array}$ & & & & & $\begin{array}{l}\text { VO2 Peak Consumption } \\
\text { Anthropometry } \\
\text { DXA Body Composition } \\
\text { Blood Pressure } \\
\text { Arterial Stiffness }\end{array}$ \\
\hline Laboratory & & & & & & Blood Analysis \\
\hline
\end{tabular}

\footnotetext{
${ }^{\mathrm{a}}$ TO Baseline, $T 1$ After 6-month intervention, T2 3-month follow-up
} 
Table 3 Exercise intervention plan for "Body \& Brain" study

\begin{tabular}{|c|c|c|c|c|}
\hline Warm-up & $\begin{array}{l}\text { Balance \& } \\
\text { Coordination }\end{array}$ & Strength & Aerobic Resistance & Stretching \& Cool down \\
\hline $\begin{array}{l}\text { General activation, joint mobilization, } \\
\text { stretching exercises }\end{array}$ & $\begin{array}{l}\text { Static and } \\
\text { dynamic } \\
\text { balance; } \\
\text { coordination } \\
\text { exercises }\end{array}$ & $\begin{array}{l}\text { Strength } \\
\text { exercises } \\
\text { involving } \\
\text { mainly major } \\
\text { upper and } \\
\text { lower body } \\
\text { muscle } \\
\text { groups }\end{array}$ & $\begin{array}{l}\text { Low impact aerobic exercises involving } \\
\text { walking, stationary march and dance }\end{array}$ & $\begin{array}{l}\text { Lower body and upper } \\
\text { body stretch, breathing } \\
\text { exercises }\end{array}$ \\
\hline $\begin{array}{l}\text { e.g. slow walk, mobility exercises for } \\
\text { the shoulders, trunk, hip, and ankles as } \\
\text { rotations, flexion/extension and } \\
\text { adduction/abduction }\end{array}$ & $\begin{array}{l}\text { e.g. one leg } \\
\text { stand, tandem } \\
\text { walk, sideways } \\
\text { walk, heel-to- } \\
\text { toe walk, step } \\
\text { over objects } \\
\text { as cones, } \\
\text { hoops and } \\
\text { huddlers, ex- } \\
\text { ercises with } \\
\text { balance pads, } \\
\text { shift weight } \\
\text { from foot to } \\
\text { foot, turning } \\
\text { and changing } \\
\text { direction }\end{array}$ & $\begin{array}{l}\text { e.g. biceps } \\
\text { arm curl, } \\
\text { triceps } \\
\text { extension, } \\
\text { adapted } \\
\text { planks, seated } \\
\text { row, chest } \\
\text { press, squats, } \\
\text { knee } \\
\text { extension, hip } \\
\text { extension, toe } \\
\text { raises, } \\
\text { standing leg } \\
\text { curl }\end{array}$ & $\begin{array}{l}\text { e.g. stationary marching, walking, simple step- } \\
\text { based choreographic movements - exercises } \\
\text { will start with only lower limbs and as needed } \\
\text { will include upper limbs }\end{array}$ & $\begin{array}{l}\text { e.g. back and chest stretch, } \\
\text { quadriceps and hamstrings } \\
\text { stretch, diaphragmatic } \\
\text { breathing }\end{array}$ \\
\hline \multicolumn{5}{|l|}{ 1st \& 2nd months } \\
\hline \multirow[t]{2}{*}{$10 \mathrm{~min}$} & $\begin{array}{ll}15 & 2-3 \\
\min & \text { exercises }\end{array}$ & $\begin{array}{ll}15 & 4 \\
\min & \text { exercises }\end{array}$ & $10 \min (5+5)$ & \multirow[t]{2}{*}{$5 \min$} \\
\hline & $\begin{array}{l}\text { Dynamic } \\
\text { balance }\end{array}$ & $\begin{array}{l}2 \times 10-12 \\
\text { reps }\end{array}$ & 60-65\% HRmax & \\
\hline \multicolumn{5}{|l|}{ 3rd month } \\
\hline \multirow[t]{2}{*}{$10 \mathrm{~min}$} & $\begin{array}{ll}15 & 2-3 \\
\text { min } & \text { exercises }\end{array}$ & $\begin{array}{ll}15 & 4-6 \\
\text { min } & \text { exercises }\end{array}$ & $10+5 \min$ & \multirow[t]{2}{*}{$5 \min$} \\
\hline & $\begin{array}{l}\text { Dynamic } \\
\text { balance and } \\
\text { coordination }\end{array}$ & $\begin{array}{l}2 \times 10-12 \\
\text { reps }\end{array}$ & 65-75\% HRmax & \\
\hline \multicolumn{5}{|l|}{ 4th month } \\
\hline \multirow[t]{2}{*}{$10 \mathrm{~min}$} & $\begin{array}{ll}10 & 2-3 \\
\text { min } & \text { exercises }\end{array}$ & $\begin{array}{ll}15 & 4-6 \\
\text { min } & \text { exercises }\end{array}$ & $10+10 \min$ & \multirow[t]{2}{*}{$5 \mathrm{~min}$} \\
\hline & $\begin{array}{l}\text { Dynamic } \\
\text { balance and } \\
\text { coordination }\end{array}$ & $2 \times 8-10$ reps & $65-75 \%$ HRmax & \\
\hline \multicolumn{5}{|l|}{ 5th and 6th months } \\
\hline \multirow[t]{2}{*}{$10 \mathrm{~min}$} & $\begin{array}{ll}10 & 2-3 \\
\text { min } & \text { exercises }\end{array}$ & $\begin{array}{ll}15 & 4-6 \\
\text { min } & \text { exercises }\end{array}$ & $10+10 \min$ & \multirow[t]{2}{*}{$5 \min$} \\
\hline & $\begin{array}{l}\text { Dynamic } \\
\text { balance and } \\
\text { coordination }\end{array}$ & $2 \times 8-10$ reps & 65-80\% HRmax & \\
\hline
\end{tabular}

Exercise professionals will registry adverse events (such as pain or fatigue) and number of falls during exercise sessions to provide information on safety of the MT program. Finally, attendance to sessions will be recorded and reasons for absences the will be catalogued [48].

Although this is not a dyadic intervention, caregivers will be included in each session as class members, but focus will be directed to individuals diagnosed with dementia. Along with the novelty of this strategy, this approach will facilitate dementia patients' participation once their transportation, motivation, and involvement are dependent of their caregivers [49, 50]. Additionally, caregivers' participation will also be determinant to deal with behavioral and psychological symptoms of dementia patients [46]. 


\section{Control group: social activity}

Participants in the control group will receive monthly sessions regarding physical activity and health-related topics as a complement to standard care. No specific exercise intervention will be conducted for this group. Due to ethical reasons, there will be no limit on cointerventions during the trial. Pharmacological, medical or other types of treatments may be initiated, continued or discontinued independently of research team approval. However, participants who eventually are going to participate in further co-interventions will be signalized, and information on type and duration will be collected and considered as covariates in statistical procedures. Participants are going to be contacted with a regular basis via phone calls to assure retention and motivation.

\section{Outcomes}

\section{Primary outcome}

Our primary outcomes are physical and cognitive function. Physical function will be measured using SPPB [51, 52] that assesses balance, gait capacity and lower limb strength. The total score ranges from 0 to 12 , with higher scores indicating better function. A 1-point change has been described as a meaningful change in physical performance [42]. Cognitive function will be evaluated using the Portuguese version of the ADAS$\operatorname{Cog}[53,54]$ which comprises fundamental features of cognitive decline such as memory, praxis, constructive ability, language and orientation. Scores range from 0 to 68 , with higher scores suggesting greater severity of cognitive impairment. A 4-point ADAS-Cog change has been described as clinically meaningful $[55,56]$. As presented on Table 1, primary and secondary outcomes are going to be measured at baseline, after 6-month of intervention, and 3-month follow-up after the intervention has ended.

\section{Secondary outcomes Physical fitness}

Physical fitness is going to be measured via the Senior Fitness Test (SFT) [57]. The SFT is reliable for assessing physical fitness in older adults ( $\geq 60$ years old) including those with cognitive impairment $[58,59]$. The SFT includes lower and upper-body strength (chair-stand and arm curl test, respectively), aerobic endurance (2-min steps test), and agility/dynamic balance (8-foot up-andgo test). Static balance will be measured with the One Leg Balance Test $[60,61]$ which has been considered a reliable for IwD. Oxygen consumption $\left(\mathrm{VO}_{2}\right.$ peak) will be measured trough an incremental treadmill test using a modified Bruce protocol designed for older individuals, previously tested with participants diagnosed with $\mathrm{AD}$ $[62,63]$ and which reliability at mild stages has been proved [64]. Finally, handgrip strength will be obtained with a Jamar hand-dynamometer [65], commonly used in IwD.

\section{Cognitive function}

The Mini Mental State Examination (MMSE) [66, 67], a widely used test of cognitive function among older adults will be used and consists of a 30-item instrument (with higher scores indicating better cognitive performance) that is organized in six cognitive domains - orientation, retention, attention and calculation, delayed recall, language, and visuo-constructive ability. Frequently used in this research field, MMSE test results will allow comparisons between different studies. As stated on Bossers et al. (2012) systematic review study, the MMSE and ADAS-Cog are the most used outcome measures to evaluate global cognitive functioning in clinical trials with older adults with dementia. In addition, these tests were found to be valid and reliable in patients with different subtypes of dementia (i.e., Alzheimer's disease, vascular disease and Lewy body disease) from mild to moderate stages [68]. Executive function will be assessed with the Trail Making Test (TMT) [69] part A - attention, visual scanning, speed of eye-hand coordination and information processing; and part B - working memory and the ability to switch between different stimuli. Time and number of errors will be registered. This test is highly related to participants ability to perform instrumental ADL, and has been used in similar studies [70, 71].

\section{$A D L$ 's functionality}

Participants independence on performing ADL will be assessed with widely used measurements: the Barthel Index [72, 73] to address ten basic daily activities, such as bathing, dressing and using toilet - with total score ranging from 0 to 100; and the Lawton \& Brody Instrumental Activities of Daily Living (IADL) scale [74] total score ranging from 0 to 8 - to address more complex activities, as shopping, food preparation and ability to handle finances. Lower scores indicate higher problems to perform activities, within both instruments.

\section{Body composition \& antropometrics}

Body composition (e.g., body mass, fat-free mass, fat mass, and appendicular skeletal mass index) will be analyzed through DXA (QDR 4500/A, Hologic Explorer, Bedford, USA) - previously used with AD participants [75]. Anthropometric measurements will be taken using standardized protocols. Waist and hip circumference will be assessed at the midpoint between iliac crest and the bottom of the ribcage, and at the widest portion of the buttocks, with the tape parallel to the floor, respectively, using a spring-loaded measuring tape. 


\section{Quality of life \& BPSD}

The Quality of Life - Alzheimer's Disease Scale (QoLAD) [76] will be used to measure the dementia participants' quality of life. The questionnaire includes 13 items such as physical health, energy, mood, memory, family, marriage, friends, and ability to do things for fun. The QoL-AD provides the participant and the caregiver reports of the participant's QoL and is scored on a 4point Likert-type scale ranging from 1 to 4 (excellent), with total scores ranging between 13 and 52 points. The Neuropsychiatric Inventory [77] will be used to determine the frequency and severity of BPSD with a total score ranging from zero to 144 points with high scores corresponding to worsening of BPSD.

\section{Caregivers burden}

The Care-related Quality of Life instrument (CarerQol) will be used to address subjective burden (CarerQol-7D), and caregivers' well-being (CarerQol-VAS), using a visual analogue scale to ask about happiness between 0 and 10 (completely happy) $[78,79]$. The subjective burden is measured in seven dimensions: fulfillment, relational problems, mental health, daily activities problems, physical health and support. Total CarerQol-7D score ranges from 0 to 14 points with higher scores indicating better caregiving situation.

\section{Subsample studies \\ Blood-based biomarkers and hemodynamics}

At baseline, after the intervention (6-months) and 3months after intervention has ended, venous blood samples from the antecubital vein will be taken from a subsample. All the biochemical analysis will be performed in a certified commercial laboratory.

Non-fasting venous blood samples will be collected into serum-separating tubes (serum isolation) or tubes containing EDTA (whole blood or plasma isolation). Traditional plasma biochemical parameters, including triglycerides (TG), total cholesterol (TC), high-density lipoprotein cholesterol (HDL-C) will be enzymatically measured [80]. Low density lipoprotein-cholesterol (LDLC) will be determined according to the Friedewald formula estimated by subtracting HDL-C and one fifth of the triglyceride value from the total cholesterol level [81]. Whole blood glycated hemoglobin (HbA1c) will be measured using high performance liquid chromatography (HPLC) [82].

Serum levels of C-reactive protein (CRP, highsensitivity test), intercellular adhesion molecule-1 (sICAM-1), vascular cell adhesion molecule-1 (sVCAM1), metalloproteinase-9 (MMP-9), interleukin (IL) 10, IL8, IL-6, brain-derived neurotrophic factor (BDNF) and vascular endothelial growth factor (VEGF) will be evaluated by an enzyme-linked immunosorbent assay (ELISA) using commercially assay kits according to the manufacturer's instructions (R\&D System, Minneapolis, MN, USA). Serum levels of creatinine will be measured using the Jaffé-method [83]. Serum levels of tumor necrosis factor-alfa (TNF-alfa) and insulin like growth factor 1 (IGF-1) will be analyzed by chemiluminescent immunoassay (CLIA) method accordingly to the manufacturer's protocol (Siemens Immunolite 2000, Munich, Germany).

These blood biomarkers will be included in the project due to current evidence of their involvement with dementia risk factors, such as dyslipidemia, inflammation, and endothelial dysfunction [84]. Additionally, we will evaluate blood biomarkers known to play an important role in the relationship between exercise and brain health, including the growth factors BDNF, IGF-1 and VEGF [85].

The same subsample will be assessed for blood pressure and arterial stiffness. Blood pressure is going to be assessed by a digital sphygmomanometer (Colin, BP 8800 , Critikron, Inc., USA) and arterial stiffness is going to be measured as carotid-femoral pulse wave velocity (cfPWV) using applanation tonometry (SphygmoCor, AtCor Medical, Australia). Procedures will follow international guidelines [86]. In brief, sequential and consecutive carotid and femoral pressure waves are going to be registered together with the electrocardiogram, that will serve as a reference to calculate the transit time between the recording's sites. The distance travelled by the pressure wave will be the direct distance between the recording points at the femoral and carotid arteries, corrected by the factor 0.8 [86]. The value of cfPWV is going to be calculated as the direct distance (in meters) divided by the transit time (in seconds). All measurements will be performed in duplicate by the same trained researcher.

\section{Confounders}

Habitual physical activity levels will be collected before, after the 6-month intervention and at 3-month follow-up using an accelerometry-based method - ActiGraph GT9X Link -, for 7 consecutive days [87]. Participants will be instructed to wear the accelerometer attached to an elastic belt at all times except when sleeping, bathing, swimming or other water activities. Data will be collected in $100 \mathrm{~Hz}$ epochs and a minimum of 10 -h on at least 4 days (1 weekend) will be considered valid data. Physical activity data will be processed using Actilife software (Actigraph LLC Pensacola, FL) and summarized as time spent in sedentary, light, moderate to vigorous physical activity.

\section{Statistical analysis plan}

Descriptive statistics will be expressed as mean and standard deviation (SD) or as median and interquartile range (IQR) for continuous variables. Categorical 
variables will be expressed as frequency and percentages. Normal distribution will be analyzed by the Kolmogorov-Smirnov test with Lilliefors' (K-S) significance correction and normal probability plots. Statistical comparisons at baseline characteristics will be performed using t-test or Mann-Whitney U-test for continuous variables and Chi-squared test or Fisher's test for categorical variables.

Age, gender, level of education, dementia type/stage, and other variables will be considered as potential confounders and adjustments will be performed in accordance to detect differences between experimental and control group.

The primary effect parameter will be the difference in the SPPB and ADAS-Cog tests between the experimental and control groups, considering the two different moments of evaluation (baseline and after 6-month of intervention). An analysis of variance (ANOVA) test with repeated measures adjusted for potential confounders will be performed for the intervention-related effects. When a significant $F$ value is obtained, Bonferroni post hoc procedures will be used to evaluate pairwise differences. Additionally, mixed effects models will be performed in order to identify potential predictive factor associated with the changes in primary and secondary outcomes from baseline, post-intervention and over the 3-months detraining period.

A multivariable regression analysis will be performed in order to explore the association between cardiovascular and blood-markers, and cognition.

Statistical analyses will be conducted with the SPSS IBM Statistical Software version 25.0 (SPSS, Inc., Chicago, IL) for Windows with a significance level of $p<0.05$.

\section{Data management and confidentiality}

An identification code will be attributed to each participant with common designation for IG and CG. The correspondence list between name and ID will be stored in a lockable cabinet at the Principal Investigator office located at the Research Centre, and separately of the report forms and evaluation instruments. Any personal information such as name, address or other identification data will not be collected nor registered. Data will be entered into an electronic database by two authorized researchers. The management and any statistical treatment will be only conducted after the authorization of the Principal Investigator. Data will be destroyed after 10 years of the end of intervention, and electronic data will be deleted 5 years after the last scientific publication.

\section{Ethics and dissemination}

The study protocol was approved by the Ethical Committee of the Faculty of Sports of the University of Porto (Ref CEFADE22.2018). All participants and caregivers/ legal representatives/significant person will be asked to sign an informed consent. Data confidentiality and anonymity will be guaranteed in all phases of the study. All procedures performed will follow the ethical standards of the institutional and/or national research committee and the 1964 Helsinki Declaration and its later amendments or comparable ethical standards. We intend to disseminate study results via presentations in national and international conferences and manuscripts in peer reviewed scientific journals. Additionally, we will promote seminaries directed for the entire community and especially for the participants, caregivers, health care professionals and organizations. We also intend to disseminate important results through local public media. Participants and caregivers will be informed individually of study results via synthetized reports.

\section{Discussion}

This study describes the protocol of a quasi-experimental controlled trial of a 6-month MT intervention for IwD comprehended on "Body \& Brain" project. Some innovative aspects of this trial are worthy highlighting. For instance, we believe that tailored, individually adjusted, and sustained MT led by a well-trained exercise specialist, may positively impact physical and cognitive function of people living with dementia, independently of their type/stage of dementia. Another innovative aspect of this trial will be the inclusion of caregivers in the exercise sessions. This is of particular relevance for improving the dynamic relationship between caregiver and IwD, to increase participants' adherence to the intervention and the caregivers' awareness regarding positive nonpharmacological interventions in dementia care [88]. Thus, by including caregivers in exercise sessions, we expect that both the caregiver and the care-recipient will remain active after the end of the trial. This intervention may also positively impact IwD neuropsychiatric symptoms, and therefore improve quality of life. Informal caregivers' quality of life and ability to cope with BPSD's may also be improved, especially if they exchange experiences with other caregivers. Finally, at a molecular level, we aim to examine how exercise can positively impact the neurotropic and inflammatory factors, as well as the endothelial function, commonly altered in $\operatorname{IwD}$ [89]. Our findings will give much needed insights about its impact on the pathophysiology of dementia and help to improve the current evidence regarding exercise as non-pharmacological intervention in IwD.

Some challenges in this trial must be recognized. First, due to the study design and the dementia paradigm in the Portuguese population, we anticipate a heterogeneous sample, under $(/ \mathrm{mis})$ diagnosed and with many different comorbidities [90, 91]. Secondly, IwD tend to be sedentary for most of the day and practice low-intensity 
physical activities [92], which is particularly concerning in the Portuguese paradigm, where older population are highly sedentary [93], Therefore, authors expect some difficulties during recruitment. Nevertheless, this project is expected to raise awareness on exercise intervention for IwD among caregivers, institutions that provide care services for older adults, policy makers and general community. We expect to contribute to the cultural change regarding the therapeutic options to manage dementia. Moreover, our goals goes along with the WHO recommendations for the functional health era in which exercise has a decisive role [4]. Finally, presuming that our data will show that IwD can respond positively to a moderately challenging tailored MT exercise, our project can be a significant step to move towards in what concerns older adults exercise prescription. Authors believe that this research may contribute to disseminate and generalize exercise prescription among this population in order to prevent disability and attenuate or delay the cognitive decline. As long as the cure for dementia remains to be achieved, and the pharmacological limitations of treatment remain, we cannot neglect the global and coadjuvant role MT exercise may have as a nonpharmacological treatment.

\section{Trial status}

The trial commenced recruitment in September 2018 and is currently in process. Recruitment will cease when the expected number of participants has been achieved.

\footnotetext{
Abbreviations

AD: Alzheimer's Disease; ADAS-Cog: Alzheimer's Disease Assessment Scale Cognitive; ADL: Activities of Daily Living; ANOVA: Analysis of Variance; BDNF: Brain-derived Neurotrophic Factor; BPSD: Behavioral and Psychological Symptoms of Dementia; CarerQol: Care-related Quality of Life instrument; CDR: Clinical Dementia Rating; cfPWV: Carotid-femoral Pulse Wave Velocity; CG: Control Group; CLIA: Chemiluminescent Immunoassay; CRP: C-reactive Protein; DSM-5: Diagnostic and Statistical Manual of Mental Disorders Fifth Edition; DSM-IV-TR: Diagnostic and Statistical Manual of Mental Disorders Fourth Edition - Text Revision; DXA: Dual Energy X-ray Absorptiometry; ELISA: Enzyme-linked Immunosorbent Assay; HbA1c: Glycated Hemoglobin; HDL-C: High-Density Lipoprotein Cholesterol; HPLC: High Performance Liquid Chromatography; HRmax: Maximum Heart Rate; ICD-10: International Statistical Classification of Diseases and Related Health Problems-10th Revision; IG: Intervention Group; IGF-1: Insulin Like Growth Factor 1; IL-6, IL-8, IL10: Interleukin 6, 8, 10; IwD: Individuals with Dementia; IADL: Instrumental Activities of Daily Living; IQR: Interquartile Range; LDL-C: Low-Density LipoproteinCholesterol; MMP-9: Metalloproteinase-9; MMSE: Mini Mental State Examination; MT: Multicomponent Training; NINCDS-ADRDA: National Institute of Neurological and Communicative Disorders and Stroke Alzheimer's Disease and Related Disorders Association; NPI: Neuropsychiatric Inventory; QoL-AD: Quality of Life-Alzheimer's Disease; SD: Standard Deviation; SFT: Senior Fitness Test; sICAM-1: Intercellular Adhesion Molecule1; SPPB: Short Physical Performance Battery; sVCAM-1: Vascular Cell Adhesion Molecule-1; TC: Total Cholesterol; TG: Triglycerides; TMT: Trail Making Test; TNF-alfa: Tumor Necrosis Factor-alfa; VEGF: Vascular Endothelial Growth Factor; WHO: World Health Organization
}

\section{Acknowledgements}

The authors would like to thank to Instituto Português do Desporto e Juventude.

\section{Authors' contributions}

Study conception and design: JC, OR, FM, AS, IMA, JM; Study coordination: JC (PI), OR (CO-PI); Writing - original draft: JC, FM, DB, AS, IMA, LB, AP, OR. Writing - Review \& Editing: JC, FM, DB, AS, IMA, LB, AP, LT, JM, OR. All the authors have made a substantial contribution, critically revised this work and approved the final manuscript.

\section{Funding}

This work was supported by Portuguese Foundation for Science and Technology (FCT): CIAFEL - Research Centre in Physical Activity, Health and Leisure [FCT/UIDB/00617/2020], Ph.D. Grants [SFRH/BD/136635/2018] to FM and [2020.05911.BD] to DB; and "Body \& Brain" Project [POCl-01-0145-FEDER-031808] financed by Portugal 2020, under the Operational Program for Competitiveness and Internationalization, European Structural and Investment Funds.

\section{Availability of data and materials}

Data sharing is not applicable to this article as no datasets were generated or analyzed during the current study.

\section{Declarations}

Ethics approval and consent to participate

The study protocol was approved by the Ethical Committee of the Faculty of Sports of the University of Porto (Ref CEFADE22.2018). The trial was registered in the US National Institutes of Health Clinical Trials Registry (ClinicalTrials.gov - identifier number NCT04095962). Informed consent will be obtained from all participant and/or legal representatives/significant person included in the study prior to data collection.

\section{Consent for publication}

Not required.

\section{Competing interests}

The authors declare that they have no competing interests.

\section{Author details}

${ }^{1}$ Faculdade de Desporto da Universidade do Porto, Rua Dr. Plácido Costa 91, 4200-450 Porto, Portugal. CIAFEL, Centro de Investigação em Atividade Física, Saúde e Lazer, Universidade do Porto, Rua Dr. Plácido Costa 91. 4200-450 Porto, Portugal. ${ }^{3}$ Faculdade de Educação Física e Desporto, Universidade Lusófona, Rua de Augusto Rosa 24, 4000-098 Porto, Portugal. ${ }^{4}$ Instituto de Ciências Biomédicas Abel Salazar, Universidade do Porto, Rua Jorge de Viterbo Ferreira 228, 4050-313 Porto, Portugal. ${ }^{5}$ CINTESIS, Centro de Investigação em Tecnologias e Serviços de Saúde, Departamento de Educação e Psicologia, Universidade de Aveiro - Campus Universitário de Santiago, 3810-193 Aveiro, Portugal.

Received: 2 February 2021 Accepted: 22 February 2021

Published online: 04 March 2021

\section{References}

1. Alzheimer's Assocation. 2020 Alzheimer's disease facts and figures. Alzheimers Dement. 2020;16(3):391-460

2. Livingston G, Huntley J, Sommerlad A, Ames D, Ballard C, Banerjee S, et al, Dementia prevention, intervention, and care: 2020 report of the Lancet Commission. Lancet. 2020;396(10248):413-46.

3. American Psychiatric Association. Neurocognitive disorders. DSM-5: diagnostic and statistical manual of mental disorders. London: American Psychiatric Publishing; 2013. p. 5.

4. World Health Organization. Global action plan on the public health response to dementia: 2017-2025. Geneva: WHO; 2017.

5. Frankish $\mathrm{H}$, Horton R. Prevention and management of dementia: a priority for public health. Lancet. 2017;390(10113):2614-5.

6. Winblad B, Amouyel P, Andrieu S, Ballard C, Brayne C, Brodaty H, et al. Defeating Alzheimer's disease and other dementias: a priority for European science and society. Lancet Neurol. 2016;15(5):455-532.

7. Goncalves-Pereira M, Cardoso A, Verdelho A, Alves da Silva J, Caldas de Almeida M, Fernandes A, et al. The prevalence of dementia in a Portuguese community sample: a 10/66 Dementia Research Group study. BMC Geriatr. 2017;17(1):261. 
8. Prince M, Ali G-C, Guerchet M, Prina AM, Albanase E, Wu Y-T. Recent global trends in the prevalence and incidence of dementia, and survival with dementia. Alzheimers Res Ther. 2016;8(23):1-23.

9. World Health Organization. Risk reduction of cognitive decline and dementia. Geneva: WHO; 2019.

10. Alty J, Farrow M, Lawler K. Exercise and dementia prevention. Pract Neurol. 2020;0:1-7.

11. Skinner SN, Ellis MP, Pa J. The effects of physical activity on cognition, dementia risk, and brain health. In: Smith GE, Farias ST, editors. APA handbook of dementia. APA handbooks in psychology series. Washington, DC: American Psychological Association; 2018. p. 381-98.

12. Burge E, Kuhne N, Berchtold A, Maupetit C, Gunten AV. Impact of physical activity on activity of daily living in moderate to severe dementia: a critical review. Eur Rev Aging Phys Act. 2012;9(1):27-39.

13. Heyn P, Abreu BC, Ottenbacher KJ. The effects of exercise training on elderly persons with cognitive impairment and dementia: a meta-analysis. Arch Phys Med Rehabil. 2004;85(10):1694-704.

14. Hesseberg K, Bentzen H, Ranhoff AH, Engedal K, Bergland A. Physical fitness in older people with mild cognitive impairment and dementia. J Aging Phys Act. 2016;24(1):92.

15. Marques-Aleixo I, Beleza J, Sampaio A, Stevanovic J, Coxito P, Goncalves I, et al. Preventive and therapeutic potential of physical exercise in neurodegenerative diseases. Antioxid Redox Signal. 2021;34(8):674-693.

16. Gomes-Osman J, Cabral DF, Morris TP, Mclnerney K, Cahalin LP, Rundek T, et al. Exercise for cognitive brain health in aging: a systematic review for an evaluation of dose. Neurol Clin Pract. 2018;8(3):1-9.

17. Livingston G, Sommerlad A, Orgeta V, Costafreda SG, Huntley J, Ames D, et al. Dementia prevention, intervention, and care. Lancet. 2017;390:2673-734.

18. Forbes D, Forbes SC, Blake CM, Thiessen EJ, Forbes $S$. Exercise programs for people with dementia. Cochrane Database Syst Rev. 2015; Issue4.Art.No: CD006489. https://doi.org/10.1002/14651858.CD006489.pub.

19. Groot C, Hooghiemstra AM, Raijmakers PGHM, Berckel BNM, Scheltens P, Scherder EJA, et al. The effect of physical activity on cognitive function in patients with dementia: A meta-analysis of randomized control trials. Aging Res Rev. 2016;25:13-23.

20. Farina N, Rusted J, Tabet $\mathrm{N}$. The effect of exercise interventions on cognitive outcome in Alzheimer's disease: a systematic review. Int Psychogeriatr. 2014; 26(1):9-18.

21. Cass SP. Alzheimer's disease and exercise: a literature review. Curr Sports Med Rep. 2017;16(1):19-22

22. Li X, Guo R, Wei Z, Jia J, Wei C. Effectiveness of exercise programs on patients with dementia: a systematic review and meta-analysis of randomized controlled trials. Biomed Res Int. 2019;2019:2308475.

23. Frederiksen KS, Sobol N, Beyer N, Hasselbalch S, Waldemar G. Moderate-tohigh intensity aerobic exercise in patients with mild to moderate Alzheimer's disease: a pilot study. Int J Geriatr Psychiatry. 2014;29(12):1242-8.

24. Erickson Kl, Hillman C, Stillman CM, Ballard RM, Bloodgood B, Conroy DE, et al. Physical activity, cognition, and brain outcomes: a review of the 2018 physical activity guidelines. Med Sci Sports Exerc. 2019;51(6):1242-51.

25. Borges-Machado F, Silva N, Farinatti P, Poton R, Ribeiro Ó, Carvalho J. Effectiveness of multicomponent exercise interventions in older adults with dementia: a meta-analysis. The Gerontologist. 2020.gnaa091, https://doi. org/10.1093/geront/gnaa091

26. Baker MK, Atlantis E, Singh MAF. Multi-modal exercise programs for older adults. Age Ageing. 2007;36:375-81.

27. Hernandez S, Sandreschi P, da Silva F, Arancibia B, da Silva R, Gutierres P, et al. What are the benefits of exercise for Alzheimer's disease? A systematic review of the past 10 years. J Aging Phys Act. 2015;23(4):659-68.

28. Perrochon A, Tchalla AE, Bonis J, Perucaud F, Mandigout S. Effects of a multicomponent exercise program on spatiotemporal gait parameters, risk of falling and physical activity in dementia patients. Dement Geriatr Cogn Dis Extra. 2015;5(3):350-60.

29. Kirk-Sanchez NJ, McGough EL. Physical exercise and cognitive performance in the elderly: current perspectives. Clin Interv Aging. 2014;9:51-62.

30. Sampaio A, Marques-Aleixo I, Seabra A, Mota J, Marques E, Carvalho J. Physical fitness in institutionalized older adults with dementia: association with cognition, functional capacity and quality of life. Aging Clin Exp Res. 2020.32(11):2329-2338

31. Sampaio A, Marques EA, Mota J, Carvalho J. Effects of a multicomponent exercise program in institutionalized elders with Alzheimer's disease. Dementia. 2016;18(2):417-31.
32. Borges-Machado F, Ribeiro O, Sampaio A, Maques-Aleixo I, Meireles J, Carvalho J. Feasibility and impact of a multicomponent exercise intervention in patients with Alzheimer's disease: a pilot study. Am J Azheimers Dis Other Dement. 2019;34(2):95-103.

33. Hong SY. Effects of periodical multicomponent exercise training and detraining for 18 months on physical function in older adults with dementia. Alzheimers Dement. 2018;14(7, Supplement):P558-P9.

34. Pitkala K, Savikko N, Poysti M, Strandberg T, Laakkonen ML. Efficacy of physical exercise intervention on mobility and physical functioning in older people with dementia: a systematic review. Exp Gerontol. 2013;48(1):85-93.

35. Lam FM, Huang MZ, Liao LR, Chung RC, Kwok TC, Pang MY. Physical exercise improves strength, balance, mobility, and endurance in people with cognitive impairment and dementia: a systematic review. J Phys. 2018; 64(1):4-15.

36. Faulk $S$, Edwards L, Sumrall K, Shelton T, Esalomi T, Payton C, et al. Benefits of physical activity on Alzheimer's disease: a literatura review. Clin Kinesiol. 2014;68(3):19-24.

37. Chan A-W, Tetzlaff JM, Altman DG, Laupacis A, Gøtzsche PC, Krleža-Jerić K, et al. SPIRIT 2013 statement: defining standard protocol items for clinical trials. Ann Intern Med. 2013;158(3):200-7.

38. Morris JC. The clinical dementia rating (CDR): current version and scoring rules. Neurology. 1993;43(11):2412-4.

39. World Health Organization. ICD-10 - international statistical classification of diseases and related health problems: 10th revision. 5th ed. Geneva: WHO; 2016.

40. McKhann G, Drachman D, Folstein M, Katzman R, Price D, Stadlan EM. Clinical diagnosis of Alzheimer's disease: report of the NINCDS-ADRDA Work Group under the auspices of Department of Health and Human Services Task Force on Alzheimer's disease. Neurology. 1984;34(7):939-44.

41. Borm GF, Fransen J, Lemmens WA. A simple sample size formula for analysis of covariance in randomized clinical trials. J Clin Epidemiol. 2007; 60(12):1234-8.

42. Kwon S, Perera S, Pahor M, Katula JA, King AC, Groessl EJ, et al. What is a meaningful change in physical performance? Findings from a clinical trial in older adults (the LIFE-P study). J Nutr Health Aging. 2009;13(6):538-44.

43. American College of Sports Medicine. ACSM's guidelines for exercise testing and prescription. 10th ed. Philadelphia: Wolters Kluwer; 2017.

44. Bull FC, Al-Ansari SS, Biddle S, Borodulin K, Buman MP, Cardon G, et al. World Health Organization 2020 guidelines on physical activity and sedentary behaviour. Br J Sports Med. 2020:54(24):1451-62.

45. van der Wardt V, Hancox J, Gondek D, Logan P, Nair R, Pollock K, et al. Adherence support strategies for exercise interventions in people with mild cognitive impairment and dementia: a systematic review. Prev Med Rep. 2017:7:38-45.

46. Laventure B, Aherne C. Living well with dementia: guidance for exercise instructors \& wellness leaders. J Act Aging. 2010;Septermber/October:62-8.

47. Tedesco S, Sica M, Ancillao A, Timmons S, Barton J, O'Flynn B. Accuracy of consumer-level and research-grade activity trackers in ambulatory settings in older adults. PLoS One. 2019;14(5):e0216891.

48. Picorelli AM, Pereira LS, Pereira DS, Felicio D, Sherrington C. Adherence to exercise programs for older people is influenced by program characteristics and personal factors: a systematic review. J Physiother. 2014;60(3):151-6.

49. Heisz JJ, Kovacevic A, Clark IB, Vandermorris S. Evaluation of a communitybased exercise program for managing Alzheimer's disease. J Am Geriatr Soc. 2016:64(4):884-6 Letters to the editor.

50. Hoffmann K, Sobol NA, Frederiksen KS, Beyer N, Vogel A, Vestergaard K, et al. Moderate-to-high intensity physical exercise in patients with Alzheimer's disease: a randomized controlled trial. J Alzheimers Dis. 2016;50(2):443-53.

51. Pavasini R, Guralnik J, Brown JC, Bari M, Cesari M, Landi F, et al. Short physical performance battery and all-cause mortality: systematic review and meta-analysis. BMC Med. 2016;14:215.

52. Guralnik JM, Simonsick EM, Ferrucci L, Glynn RJ, Berkman LF, Blazer DG, et al. A short physical performance battery assessing lower extremity function: association with self-reported disability and prediction of mortality and nursing home admission. J Gerontol. 1994;49(2):M85-94.

53. Nogueira J, Freitas S, Duro D, Almeida J, Santana I. Validation study of the Alzheimer's disease assessment scale-cognitive subscale (ADAS-Cog) for the Portuquese patients with mild cognitive impairment and Alzheimer's disease. Clin Neuropsychol. 2018;32(sup1):46-59.

54. Rosen WG, Mohs RC, Davis KL. A new rating scale for Alzheimer's disease. Am J Psychiatry. 1984;141(11):1356-64. 
55. Rockwood K, Fay S, Gorman M. The ADAS-cog and clinically meaningful change in the VISTA clinical trial of galantamine for Alzheimer's disease. Int J Geriatr Psychiatry. 2010;25(2):191-201.

56. Schrag A, Schott JM. What is the clinically relevant change on the ADASCog? J Neurol Neurosurg Psychiatry. 2012;83(2):171-3.

57. Rikli RE, Jones J. Senior fitness test manual. 2nd ed. Champaign: Human Kinetics; 2001

58. Hesseberg K, Bentzen $H$, Bergland A. Reliability of the senior fitness test in community-dwelling older people with cognitive impairment. Physiother Res Int. 2015;20(1):37-44.

59. Langhammer B, Stanghelle JK. The senior fitness test. J Physiother. 2015; 61(3):163.

60. Rolland Y, Abellan van Kan G, Nourhashemi F, Andrieu S, Cantet C, Guyonnet-Gillette $S$, et al. An abnormal "one-leg balance" test predicts cognitive decline during Alzheimer's disease. J Alzheimers Dis. 2009;16(3): 525-31

61. Vellas BJ, Rubenstein LZ, Ousset PJ, Faisant C, Kostek V, Nourhashemi F, et al. One-leg standing balance and functional status in a population of 512 community-living elderly persons. Aging (Milano). 1997:9(1-2):95-8.

62. Vidoni ED, Van Sciver A, Johnson DK, He J, Honea R, Haines B, et al. A community-based approach to trials of aerobic exercise in aging and Alzheimer's disease. Contemp Clin Trials. 2012;33(6):1105-16.

63. Morris JK, Vidoni ED, Johnson DK, Sciver AV, Mahnken JD, Honea RA, et al. Aerobic exercise for Alzheimer's disease: a randomized controlled pilot trial. PLoS One. 2017;12(2):e0170547.

64. Anderson HS, Kluding PM, Gajewski BJ, Donnelly JE, Burns JM. Realibility of peak treadmill exercise tests in mild Alzheimer disease. Int J Neurosci. 2011; 121(8):450-6.

65. Mendes J, Amaral TF, Borges N, Santos A, Padrão P, Moreira P, et al. Handgrip strength values of Portuguese older adults: a population based study. BMC Geriatr. 2017;17:191

66. Santana I, Duro D, Lemos R, Costa V, Pereira M, Simoes MR, et al. Minimental state examination: screening and diagnosis of cognitive decline, using new normative data. Acta Medica Port. 2016;29(4):240-8.

67. Folstein MF, Folstein SE, McHugh PR. "Mini-mental state". A practical method for grading the cognitive state of patients for the clinician. J Psychiatr Res. 1975;12(3):189-98.

68. Bossers WJR, Bossers WJR, van der Woude LHV, Boersma F, Scherder EJA, van Heuvelen MJG. Recommended measures for the assessment of cognitive and physical performance in older patients with dementia: systematic review. Dement Geriatr Cogn Dis Extra. 2012;2(1):589-609.

69. Cavaco S, Gonçalves A, Pinto C, Almeida E, Gomes F, Moreira I, et al. Trail making test: regression-based norms for the Portuguse population. Arch Clin Neuropsychol. 2013;28(2):189-98.

70. Tsugawa A, Shimizu S, Hirose D, Sato T, Hatanaka H, Takenoshita N, et al. Effects of 12-month exercise intervention on physical and cognitive functions of nursing home residents requiring long-term care: a nonrandomised pilot study. Psychogeriatrics. 2020.20(4):419-426.

71. Yu F, Vock DM, Barclay TR. Executive function: responses to aerobic exercise in Alzheimer's disease. Geriatr Nurs. 2018;39(2):219-24.

72. Mahoney FI, Barthel DW. Functional evaluation: the Barthel index. Md State Med J. 1965;14:61-5

73. Sequeira C. Cuidar de Idosos Dependentes. Coimbra: Quarteto Editora; 2007.

74. Lawton MP, Brody EM. Assessment of older people: self-maintaining and instrumental activities of daily living. Gerontologist. 1969:9(3):179-86.

75. Burns JM, Johnson DK, Watts A, Swerdlow RH, Brooks WM. Reduced lean mass in early Alzheimer disease and its association with brain atrophy. Arch Neurol. 2010;67(4):428-33.

76. Logsdon RG, Gibbons LE, McCurry SM, Teri L. Assessing quality of life in older adults with cognitive impairment. Psychosom Med. 2002;64(3):510-9.

77. Ferreira AR, Martins S, Ribeiro O, Fernandes L. Validity and reliability of the European Portuguese version of neuropsychiatric inventory in an institutionalized sample. J Clin Med Res. 2015:7(1):21-8.

78. Brouwer WB, van Exel NJ, van Gorp B, Redekop WK. The CarerQol instrument: a new instrument to measure care-related quality of life of informal caregivers for use in economic evaluations. Qual Life Res. 2006; 15(6):1005-21.

79. Hoefman RJ, van Exel J, Brouwer WBF. Measuring the impact of caregiving on informal carers: a construct validation study of the CarerQol instrument Health Qual Life Outcomes. 2013;11(1):173.
80. Eugene BE. Recommendations for improving cholesterol measurement: executive summary: a report from the laboratory standardization panel of the National Education Program. Lab Med. 1990;21(7):429-35.

81. Friedewald WT, Levy RI, Fredrickson DS. Estimation of the concentration of low-density lipoprotein cholesterol in plasma, without use of the preparative ultracentrifuge. Clin Chem. 1972;18(6):499-502.

82. Davis JE, MCDonald JM, Jarett L. A high-performance liquid chromatography method for hemoglobin A1c. Diabetes. 1978;27(2):102-7.

83. Delanghe JR, Speeckaert MM. Creatinine determination according to Jaffewhat does it stand for? NDT Plus. 2011;4(2):83-6.

84. Oliveira BCL, Bellozi PMQ, Reis HJ, de Oliveira ACP. Inflammation as a possible link between dyslipidemia and Alzheimer's disease. Neuroscience. 2018;376:127-41.

85. Silva MVF, Loures CMG, Alves LCV, de Souza LC, Borges KBG, Carvalho MDG. Alzheimer's disease: risk factors and potentially protective measures. J Biomed Sci. 2019;26(1):33.

86. The Reference Values for Arterial Stiffness' Collaboration. Determinants of pulse wave velocity in healthy people and in the presence of cardiovascular risk factors: 'establishing normal and reference values'. Eur Heart J. 2010; 31(19):2338-50.

87. Erickson Kl, Barr LL, Weinstein AM, Banducci SE, Aki SL, Santo NM, et al. Measuring physical activity using accelerometry in a community sample with dementia. J Am Geriatr Soc. 2013;61(1):158-9.

88. Whitlatch CJ. Including the person with dementia in family care-giving research. Aging Ment Health. 2001;5(sup1):20-2.

89. Trigiani $\amalg$, Hamel E. An endothelial link between the benefits of physical exercise in dementia. J Cereb Blood Flow Metab. 2017;37(8):2649-64.

90. Direcção-Geral da Saúde. Saúde Mental em Números. Lisboa; DGS: 2016.

91. Teixeira L, Dos Santos PM, Alves S, Azevedo MJ, Duarte MG, Leuschner A, et al. Screening of dementia in Portuguese primary care: methodology, assessment tools, and main results. Front Med. 2017:4:197.

92. van Alphen HJ, Volkers KM, Blankevoort CG, Scherder EJ, Hortobágyi T, van Heuvelen MJ. Older adults with dementia are sedentary for most of the day. PLoS One. 2016;11(3):e0152457

93. Marques EA, Baptista F, Santos DA, Silva AM, Mota J, Sardinha LB. Risk for losing physical independence in older adults: the role of sedentary time, light, and moderate to vigorous physical activity. Maturitas. 2014;79(1):91-5.

\section{Publisher's Note}

Springer Nature remains neutral with regard to jurisdictional claims in published maps and institutional affiliations.

Ready to submit your research? Choose BMC and benefit from:

- fast, convenient online submission

- thorough peer review by experienced researchers in your field

- rapid publication on acceptance

- support for research data, including large and complex data types

- gold Open Access which fosters wider collaboration and increased citations

- maximum visibility for your research: over $100 \mathrm{M}$ website views per year

At BMC, research is always in progress.

Learn more biomedcentral.com/submissions 